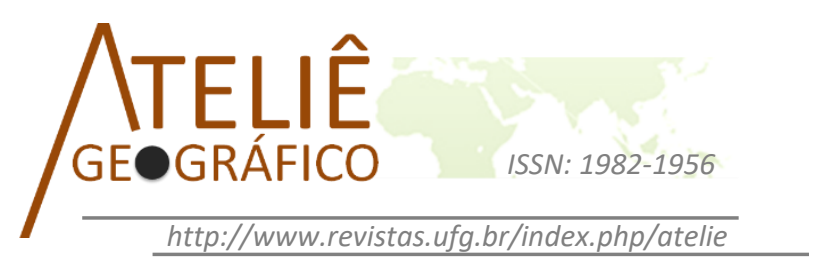

\title{
Por trás da vitrine de um megaevento: remoções, despejos $e$ reassentamento de comunidades
}

\author{
Behind the showcase of a mega-event: displacements, \\ evictions, and resettlement of communities \\ Detrás de la pantalla de un megaevento: desplazamientos, \\ desalojos y reasentamiento de comunidades
}

\author{
Ernandy Luis Vasconcelos de Lima \\ University of Oxford \\ ernandy@gmail.com
}

\begin{abstract}
Resumo
A capital catalã se tornou amplamente conhecida, seja através do modelo Barcelona sob os auspícios do planejamento estratégico adotado, seja pelo fascínio evidenciado pelos Jogos Olímpicos de 1992. Ao sediar o megaevento esportivo Barcelona'92, a cidade espanhola expôs o poder argumentativo e o panorama factível da consecução de megaprojetos de regeneração urbana em curto período de tempo. Nesse sentido, esta pesquisa procura mapear e analisar as possíveis implicações socioespaciais resultantes do processo de planejamento para a estruturação e apropriação do espaço urbano. Objetiva-se, portanto, desvendar as contradições socioespaciais encobertas pelo imaginário e aparato ideológico pautados em Barcelona'92. Explora-se, assim, a relação entre megaeventos esportivos e o desalojamento de comunidades, bem como a histórica implicação desse fenômeno sobre a estrutura socioespacial de Barcelona. Para tanto, pesquisa bibliográfica e pesquisa documental foram contempladas por meio de diversas fontes, tendo em vista explicitar a emblemática questão das remoções pari passu com as transformações urbanas na cidade de Barcelona. Além disso, entrevistas abertas e semiestruturadas foram conduzidas entre os anos de 2011 e 2016. Dado o êxito de planejamento estratégico catalão, as preparações para o Barcelona'92 atingiram diversas famílias, por meio da construção de empreendimentos desportivos e de transformação urbana. Em se tratando de remoções, 624 famílias foram impactadas, ou seja, desalojadas das áreas designadas.
\end{abstract}

Palavras-chave: Barcelona; Megaeventos; Remoções; Planejamento urbano estratégico; Comunidades. 


\begin{abstract}
The Catalan capital city has become widely known, either through the Barcelona model under the auspices of the strategic planning process, either by the fascination building upon the 1992 Olympic Games. In order of host the sporting mega-event Barcelona'92, the Spanish city showed its level of compliance with the execution of urban regeneration megaprojects in the short term. In this light, this paper maps and examines the possible socio-spatial implications resulting from the planning process for structuring and appropriation of urban space. Therefore, it's the main goal is to unveil the socio-spatial contradictions hidden by the Barcelona' 92 . So, it explores the relation between sporting mega-events and evictions, and the historical implications of this phenomenon on Barcelona's socio-spatial structure. Therefore, bibliographical research and documentary research were contemplated through several sources aiming to make explicit the emblematic issue of removals with the urban transformations in the city of Barcelona. In addition, open and semi-structured interviews were conducted between 2011 and 2016. Given the success of Catalan strategic planning, preparations for Barcelona'92 reached several families through the construction of sports venues and urban transformation projects. In the case of removals, 624 families were impacted; have been displaced from the designated areas.
\end{abstract}

Keywords: Barcelona; Mega-events; Evictions; Strategic urban planning; Communities.

\title{
Resumen
}

La capital catalana se ha convertido en una ciudad muy conocida, o sea a través del modelo de Barcelona bajo los auspicios del proceso de planificación estratégica, o sea por la fascinación de los Juegos Olímpicos de 1992. En orden de acogida el megaevento deportivo Barcelona'92, la ciudad española mostró su nivel de cumplimiento con la ejecución de megaproyectos de regeneración urbana en el corto plazo. A la luz de este trabajo, se hace un mapeo y se examinan las posibles implicaciones socioespaciales que resultan del proceso de planificación para la estructuración y apropiación del espacio urbano. Por lo tanto, su objetivo principal es desvelar las contradicciones socio-espáciales ocultadas por el Barcelona'92. Así, explora la relación entre los mega-eventos deportivos y los desalojos, y las implicaciones históricas de este fenómeno en la estructura socio-espacial de Barcelona. Por tanto, la investigación bibliográfica e investigación documental fueron contempladas a través de diversas fuentes objetivando explicitar la emblemática cuestión de las remociones pari pasu con las transformaciones urbanas en la ciudad de Barcelona. Además, entrevistas abiertas y semiestructuradas fueron conducidas entre los años 2011 y 2016. Dado el éxito de planificación estratégica catalán, las preparaciones de Barcelona'92 alcanzaron a varias familias a través de la construcción de emprendimientos deportivos y de transformación urbana. En el caso de las remociones, 624 familias fueron afectadas; por cuanto, desalojadas de las áreas designadas.

Palabras Clave: Barcelona; Mega-eventos; Desalojos; Planificación urbana estratégica. 


\section{Introdução}

Desde a segunda metade da década de 1980 e início dos anos de 1990, tem crescido o interesse de planejadores, governantes, empreendedores, pesquisadores e demais agentes urbanos no chamado modelo Barcelona. Esse modelo se tornou uma requintada vitrine a quaisquer cidades atraídas pelo planejamento estratégico catalão e àquelas interessadas em sediar megaeventos esportivos. Tomando como referência as estratégias e as intenções políticas adotadas na cidade espanhola, dois cenários ganharam destaque. Primeiro, parte-se da dedução de que as transformações urbanas advêm do êxito de um planejamento estratégico orientado a reforçar internacionalmente a imagem da cidade. Segundo, sediar o megaevento Barcelona'92, como também ficaram conhecidos os Jogos Olímpicos de 1992, apresentou-se como fator dinamizador e factível da consecução de megaprojetos de regeneração urbana em um curto período de tempo.

Em 2016, completaram-se trinta anos que a capital da Catalunha recebeu o direito de sediar as edições dos Jogos Olímpicos de 1992. Consequentemente, estima-se que um número crescente de cidades - sedes, candidatas, postulantes ou não de megaeventos vem tentando assimilar e/ou reproduzir os componentes estratégicos do fenômeno de transformação urbana catalão. Para concretizar tal propósito, difunde-se que investimentos, provisão em infraestrutura e marketing urbanos, assujeitamento institucional e estabelecimento de parcerias público-privadas são "poderosos elementos constitutivos da política do empreendedorismo urbano" (HARVEY, 2005, p. 235) que atravessa a cidade capitalista contemporânea, cuja materialização se dá através da refuncionalização e requalificação socioespacial dos territórios.

O conceito de megaevento utilizado aqui para explicitar as transformações socioespaciais está concatenado, grosso modo, ao pensamento de Roche $(2000 ; 2003)$ e de Hiller (2006), que o introduziram no sentido de determinar o direcionamento econômico capitalista praticado nas cidades-sede. Com efeito, dele deriva uma arquitetura produtiva que norteia as políticas de desenvolvimento socioespaciais e econômica urbana associadas, sobretudo, à gentrificação e às operações de regeneração e requalificação urbana. À medida que esse processo vai se confirmando, privilegiam-se preeminentes parcelas e agentes eleitos pelo modo de produção hegemônico nessas espacialidades (HERCE, 2005; GIULIANOTTI et al., 2015).

Harvey (2005) é categórico quando afirma que o empreendedorismo urbano, associado aos investimentos de capital e da concorrência interurbana, tem muito a ver com o fascínio sócio-político na atração desses eventos, especialmente no suposto estímulo dado às economias urbanas desgastadas, estagnadas ou sem impulso do qual o capital vem se apropriando. Segundo o autor, "a ênfase no turismo, na produção e no consumo de espetáculos, na promoção de eventos efêmeros num determinado palco, mostra todos os sinais de ser o remédio predileto" (HARVEY, 2005, p. 183-184) para tais economias.

Assim, à luz da intensificação de ofensivas neoliberais, tanto a produção, quanto o consumo e a lucratividade desses faustosos espetáculos intensificam sobremaneira os processos especulativos de valorização imobiliária, de disparidades e do surgimento de novas contradições socioespaciais. Quando se impulsiona um megaevento esportivo, abre- 
se uma janela suturada às "trajetórias históricas e sociopolítico-econômicas"1 (SILK, 2014 , p. 51, tradução nossa). Ora, conceber e viabilizar um megaevento esportivo têm se tornado parte da deliberada agenda urbana para promover o crescimento econômico local e reforçar globalmente o nome e a marca da cidade-sede (HALL, 1992). Entretanto, igualmente emerge um número vertiginoso de desocupações, remoções (forçadas), encarecimento habitacional e outros impactos adversos. Em essência, ao considerar os efeitos divergentes de megaeventos esportivos, Olds (1998, p. 40, tradução nossa) afirma que "estes impactos sociais negativos negam o princípio do direito à habitação. Direitos habitacionais são realmente um componente de um direito bem maior: o direito à cidade" 2 .

Além disso, o envolvimento e a participação dos moradores das comunidades afetadas no processo de planejamento, na combinação de estratégias, nas decisões e ações que viabilizam tais eventos, muitas vezes, são insignificantes ou inexistentes. Portanto, remoção e reassentamento são dois fenômenos que se tornaram triviais na exequibilidade de megaeventos esportivos.

Impõe-se, deste modo, a necessidade de mapear e discutir os impactos adversos mais significativos, dado o modelo de organização adotado por Barcelona' 92. Nesse contexto, o presente artigo é dedicado ao cumprimento desse encargo. Rumo a uma análise crítica de um megaevento esportivo, procura-se desvendar as contradições socioespaciais encobertas pelo "imaginário" e pelo aparato ideológico estrategista e propagandista pautado na marca Barcelona. Assim, apresentam-se os resultados de uma pesquisa sobre megaeventos esportivos, com o intuito de produzir respostas estritamente de cunho geográfico às seguintes perguntas: i. Como o modelo de organização de um megaevento esportivo motivou a especulação imobiliária no espaço urbano de Barcelona? ii. Apesar do indiscutível legado positivo dos Jogos Olímpicos de 1992, houve impactos adversos à comunidade local? iii. Dado o êxito do planejamento estratégico, como se deu o processo de realocação dos grupos afetados?

Para responder às perguntas acima, pesquisa bibliográfica e pesquisa documental foram contempladas, por meio de diversas fontes, tais como Moragas e Botella (2002), Preuss (2004), Cohre (2007) e Monclús (2010), com a função de explicitar substancialmente a emblemática relação das remoções pari passu com as transformações urbanas na cidade de Barcelona. Além disso, entrevistas abertas e semiestruturadas foram conduzidas pela presente pesquisa, entre 2011 e 2016, a fim de reforçar o debate em tela cerca de 20 anos após Barcelona'92.

$\mathrm{Na}$ seção "Barcelona'92", analisa-se o modelo de organização dos Jogos Olímpicos de 1992. Explica-se, assim, o resultado adverso precípuo das intervenções

1 "Sports mega-events (SMEs) have always been closely sutured with various historical sociopolitical-economic trajectories".

2 "These negative social impacts negate the principle of the right to housing. Housing rights are really one component of a much larger right: the right to the city". 
espaciais, quer seja pelo encarecimento do solo, quer seja pelo aumento no preço da habitação. Na seção seguinte, após o mapeamento dessas intervenções, examina-se o processo de remoções resultantes do megaevento esportivo Barcelona'92.

\section{Barcelona'92}

Em consequência das preparações para o Barcelona'92, observaram-se impactos adversos à acessibilidade e à disponibilidade de habitação na capital catalã (LIMA, 2015). Segundo levantamento do Centre on Housing Rights and Evictions - COHRE (2007) e do Observatório DESC (2007), entre os anos de 1986 e 1992, período de preparação para as Olimpíadas, o preço da moradia aumentou consideravelmente na cidade espanhola. Constatou-se um aumento de cerca de $240 \%$ nos preços dos imóveis novos, entre o anúncio de 1986, quando da eleição de Barcelona como cidade-sede, e 1992, ano de celebração dos jogos olímpicos.

\section{O modelo de organização do megaevento esportivo}

A organização do megaevento esportivo espanhol ficou a cargo do Comitè Organitzador Olímpic Barcelona 1992, S.A - COOB'92. No que diz respeito às metas de Barcelona em organizar os Jogos Olímpicos de 1992, essas tinham tanto a finalidade de projetar a imagem de cidade quanto a de facilitar sua transformação urbana. Isso a colocou na posição de um marco de alterações e referências espaciais que atravessou visceralmente a Catalunha ao longo das décadas de 1980 e 1990 . Em termos de tamanho e natureza, tal dinamismo testemunhou uma das mais afamadas mudanças urbanas ocorridas na Europa entre os anos de 1986 e 1993 (BRUNET, 1995, p. 3). Como se sabe, as candidaturas de Londres (em 2005) e Rio de Janeiro (em 2009), por exemplo, "embebidas" no arsenal teórico e prático da expertise catalã, o qual motivou estratégias e um regime urbanístico e especulativo, despenderam esforços na celebração das Olimpíadas de 2012 e 2016, respectivamente.

No caso de Barcelona, 32,7\% dos projetos olímpicos foram promovidos pela iniciativa privada. $\mathrm{O}$ alto grau de inversão privada deu-se pelos mecanismos de atratividade que foram criados e proporcionados à imagem de cidade com os Jogos Olímpicos de 1992 (BRUNET, 1995). A Barcelona Holding Olímpic, S.A - HOLSA ${ }^{3}$, em parceria com o Estado e com a Prefeitura da capital catalã, viabilizou grande parte das construções das instalações olímpicas e dos anéis rodoviários (rondas viarias, em espanhol e/ou catalão). A nova rede de mobilidade erigiu aproximadamente 78 quilômetros de estradas (BRUNET, 1995). Assim, a reformulação e atualização da malha

${ }^{3}$ Em 1989, Barcelona Holding Olímpic, S.A - HOLSA foi instituída promover os projetos de transformação urbana de Barcelona e prepará-la para os Jogos Olímpicos de 1992 (HOLSA, 1992). 
viária foi um dos megaprojetos mais venerados, dentro de uma visão territorial seletiva e medular. Além do mais, a construção da Vila Olímpica instituiu o novo bairro ${ }^{4}$ marítimo La Vila Olímpica del Poblenou na cidade, dentro de um projeto maior de reestruturação da orla marítima e das intervenções associadas ao seafront development $t^{5}$.

Dado o modelo de organização dos Jogos Olímpicos de Barcelona 1992, todos os projetos de construção de empreendimentos desportivos tinham que ser concluídos muito antes da celebração dos jogos (CLUSA, 1999; VALLS, 2001; ESSEX; CHALLEY, 2003; BUSQUETS, 2004; CAPEL, 2009). Segundo Brunet (1995), esse foi precisamente um dos consensos estabelecidos e, sobremaneira, pretendido: deixar como herança um elevado número de investimentos e projetos que fossem executados depois do megaevento. Nesse intuito, com os resultados finais da parceria estabelecida entre HOLSA, COOB'92, Prefeitura de Barcelona, Generalitat de Catalunya, Ministério da Economia e do Tesouro Espanhol, bem como os demais agentes envolvidos, estima-se que os investimentos diretos relacionados às Olimpíadas de Barcelona atingiram a cifra de 956.630 milhões de pesetas $^{6}$ (aproximadamente US\$ 8,012,000,000), no período 19861993 (BRUNET, 1995).

No que diz respeito à construção de empreendimentos desportivos e daqueles associados à transformação urbana em meados de 1989, identificaram-se os seguintes percentuais: os novos projetos viários significaram um aumento de 15\%; a ampliação do sistema de esgotos proporcionou um aumento de $17 \%$; a instituição de novas zonas verdes e a recuperação de praias possibilitou uma ascensão de $78 \%$; recuperação e provisão de novas fontes e chafarizes, um acrescimento por volta de $268 \%$ (BRUNET, 1995).

Antes das preparações do retrocitado megaevento esportivo, constatava-se um sobrecarregamento do sistema viário (NAYLON, 1981). De certa forma, uma das justificativas da construção das rondas, conforme Bohigas (1999, p. 206), era o fato de que, do ponto de vista funcional, tornava-se imprescindível a provisão de anéis viários que facilitassem a integração da denominada primeira franja periférica viária (chamada de $1^{\text {a }}$

${ }^{4} \mathrm{O}$ novo bairro foi estabelecido na área do antigo bairro de Icaria.

${ }^{5}$ Uma vez providas, em parte, pelo modelo idealizado como "Barcelona se abre para o mar", as obras de intervenção e requalificação do seafront development da orla marítima de Barcelona vão desde as remodelações do projeto Port Vell, passando pela reestruturação do antigo porto (projetos de requalificação dos Cais de Fusta i Espanya, Cais Bosh i Alsina), por Barceloneta, Puerto Olímpico, Poblenou e Diagonal Mar i el Front Marítim del Poblenou. Em tese, também se pode dizer que essa transformação teve como referência a Operação Inner Harbor de Baltimore, nos Estados Unidos da América.

${ }^{6}$ Peseta foi a moeda corrente na Espanha, entre os anos de 1869 e 2002, antes da entrada do país ibérico na Zona Euro e de sua adesão à união monetária europeia em 1 de janeiro de 2002. Em março de 2002, 1 euro $=166,386$ Pesetas. 
Corona, ou Àrea Metropolitana de Barcelona ${ }^{7}$ ), reduzindo e canalizando o trânsito da zona central de Barcelona.

A edificação da Ronda de Dalt e da Ronda del Litoral, por exemplo, definiu novos espaços de integração aos existentes, congregando a capital catalã aos municípios da franja metropolitana. Dentro do programa de regeneração da zona costeira associado às obras de Barcelona'92, a Ronda del Litoral foi construída em túnel: uma via expressa, parcialmente subterrânea e lindeira à nova zona portuária e à linha de costa requalificada.

Na verdade, inseridos nos arranjos reprodutivos do capital hegemônico e seletivo, os Jogos Olímpicos de 1992 foram uma das justificativas essenciais à execução dos projetos de intervenção e renovação urbana na capital catalã e região de influência (LIMA, 2015). Segundo Acebillo (1999), do ponto de vista da escala dessa intervenção, explicamse, sobremodo, as recentes transformações urbanas associadas ao supracitado megaevento esportivo, através de três grandes etapas:

i. Período 1980-1987: etapa em que constaram intervenções pontuais de pequena escala com a provisão de praças, novas ruas, parques e áreas verdes;

ii. Período 1987-1992: etapa constituída expressivamente pela construção de empreendimentos desportivos e das intervenções de infraestruturas urbanas propiciadas pelos Jogos Olímpicos de 1992;

iii. Período iniciado a partir de 1993: intervenções urbanas em Barcelona na área central de sua região metropolitana iniciadas na fase pós-olímpica.

Abria-se, assim, uma nova era de reflexão sobre a questão que emergia como aspecto crucial à evocação da identidade Catalã (HARGREAVES, 2000): situar Barcelona no mapa mundial (MARAGALL, 1999), por meio das transformações urbanísticas e do êxito da celebração dos Jogos Olímpicos de 1992 (ACEBILLO, 1999). Indubitavelmente, tal cenário ${ }^{8}$ foi propagado através do modus operandi, aqui denominado de modelo Barcelona. O modelo Barcelona converteu-se em requintada "vitrine" a todas cidades atraídas pelo planejamento estratégico urbano adotado e, simplesmente, àquelas motivadas em hospedar megaeventos esportivos.

\footnotetext{
${ }^{7}$ Inclui as seguintes cidades: Hospitalet de Llobregat, Badalona, San Adrián de Besós, Santa Coloma de Gramanet, e Cornellá de Llobregat.

${ }^{8}$ Execução dos projetos de intervenção e renovação urbana como preparação urbanística para a "vitrine" das cidades-sede de eventos de larga escala.
} 


\section{Resultado das intervenções espaciais: encarecimento do solo e da moradia}

O aumento do preço da habitação foi um dos maiores impactos do persuasivo crescimento urbano iniciado a partir da segunda metade dos anos de 1980 (TELLO; RIGOL 1994), processo visivelmente corroborado logo após a nomeação da cidade para sediar o megaevento. Até o ano olímpico, os preços subiram exorbitantemente, chegando a duplicar; algo que não ocorreu a partir de 1976, quando da aprovação do Plano Geral de Ordenamento Urbano da Área Metropolitana de Barcelona ${ }^{9}$ (VALLS, 1998).

Esse Plano "não oferecia grandes expectativas à especulação sobre o solo, pois restringia consideravelmente o coeficiente de ocupação, bem como o solo urbanizable ${ }^{10}$ (urbanizado) e os usos industriais obsoletos seriam substituídos por serviços, equipamentos sociais e espaços públicos" (TELLO; RIGOL, 1994, p. 61). Ainda segundo os autores, o Plano, totalmente dependente de investimentos públicos, abriu espaços para a intensificação da condição terciária de Barcelona, enquanto polo turístico. Tal condição resultou no aumento exagerado dos preços de moradia. Além de evidenciar a cidade no hall das cidades globais (SASSEN, 2005), tratava-se de uma busca incessante no que se pode chamar de tendência à globalização das relações econômicas e da "cultura de massa" (TOURAINE, 2010).

No que se refere às estratégias de converter Barcelona à condição de cidade marca $_{2}$ enquanto também centro de inovação, foram estudados mecanismos de intervenção urbanística que a adaptassem ao papel de cidade lócus do consumo. Nessa perspectiva, foram esboçadas novas áreas ${ }^{11}$ de centralidades: Diagonal-Sarriá, La Carrer Tarragona; RENFE-Meridiana; Vila Olímpica; Porto Urbano; Valle Hebron; La Sagrera; DiagonalMar; Praça Cerdá. Em consequência, "[a] maior parte dessas áreas situa-se nos extremos do tecido urbano consolidado e correspondiam a zonas de antigas fábricas, instalações ferroviárias ou portuárias obsoletas, e espaços mal aproveitados. As áreas com nova centralidade foram concebidas como espaços importantes onde se combinassem atividades terciárias" (TELLO; RIGOL, 1994, p. 62).

Executava-se, no início dos anos de 1980, por meio de estratégias espaciais e transformações no tecido urbano, a conversão da cidade em "centro terciário, em centro

\footnotetext{
${ }^{9}$ Plan General Metropolitano de 1974, aprovado em 1976.

${ }^{10}$ Dadas a classificação e as funções urbanísticas, o solo na Espanha se classifica em: (1) Solo urbanizable - áreas consideradas, em princípio, adequadas à urbanização pelo planejamento geral de cada município espanhol; (2) Solo urbano - formado por áreas consolidadas e caracterizado pela disponibilidade de infraestrutura e serviços urbanos; e (3) suelo no urbanizable - áreas sob proteção legal e especial, devido a seus valores paisagísticos, ambientais, históricos, arqueológicos, científicos e ou culturais.

${ }^{11}$ Áreas de Nueva Centralidad (tradução direta do Castelhano) foram espaços destinados aos novos projetos e às intervenções espaciais na segunda metade da década de 1980, os quais reforçaram a pretensão territorial e política de uma cidade mais compacta.
} 
de serviços e espaço de consumo" (TELLO, RIGOL, 1994, p. 62), adaptando-a ao novo papel de função terciária. Ademais, conforme sustentado pelos autores, "em 1982 começou a esboçar-se um plano que permitia negociar com vários organismos do Estado a construção das infraestruturas, especialmente a dos grandes eixos viários a que hoje chamamos de rondas" (TELLO, RIGOL, 1994, p. 62).

No período entre os anos de 1986 e 1992, foram concluídos $42 \mathrm{~km}$ de novas vias e viabilizadas três das novas centralidades (Vila Olímpica, Valle Hebron, DiagonalSarriá), que estavam previstas no Plano de 1974/1976. Devido ao grande investimento público nas obras de infraestrutura e de renovação urbana, houve um rebaixamento orçamentário no que concerne à provisão de habitação social ${ }^{12}$ (viviendas protegidas). Dessa maneira, no que tange ao investimento imobiliário privado, houve uma canalização a favor da construção de escritórios ${ }^{13}$ e de moradias em regime livre ${ }^{14}$ (TELLO; RIGOL, 1994).

Consoante Herce (2005), com a duplicação de solo urbanizable na cidade de Barcelona, o preço da moradia durante os anos de 1985 e 2004 atingiu o patamar de aproximadamente $550 \%$ de aumento acentuado, subindo com uma velocidade nunca antes vista. Entre 1985 e 1994, houve uma elevação de $160 \%$ no preço da moradia.

As efervescentes dinamizações do setor imobiliário, paralelamente ao crescimento rápido da atuação urbanística na cidade, permearam grandes expectativas no mercado. Além disso, os projetos de requalificação urbana das novas centralidades "abriram novas expectativas ao mercado imobiliário e ao sector da construção; a nomeação de Barcelona como cidade olímpica constituía uma garantia de investimento e o prazo de seis anos oferecia uma oportunidade de negócios que poucas vezes acontece" (TELLO; RIGOL, 1994, p. 64). Assim, o crescimento do preço da habitação, visivelmente percebido já na segunda metade na década de 1980, estava vinculado também à aplicação do Plano de 1974/1976.

Ainda segundo os autores, não foi somente o preço do solo o único responsável pelo encarecimento do preço da moradia; foi a partir do ano de 1987 que "a habitação começou a ser um problema grave para aqueles cujos rendimentos não permitiam financiar a compra" (TELLO; RIGOL, 1994, p. 64). Ou seja, aqueles que detinham uma propriedade tentavam vendê-la a preços exorbitantes ou alugá-la "a preços astronômicos à população flutuante que se ocupava da preparação da cidade e dos jogos" (TELLO; RIGOL, 1994, p. 64).

\footnotetext{
${ }^{12}$ Convém citar as disposições e investimentos relativos à denominada locação-venda de habitação social (viviendas sociales) e ou de alojamentos plurifamiliares ou de unidades habitacionais em edifícios destinados a alojar familiares com baixos rendimentos.

${ }^{13}$ Neste caso, enquadra-se o mercado de construção e venda ou arrendamento de apartamentos e espaços comerciais.

${ }^{14}$ Enquadram-se numa categoria tida como: habitação de venda livre no mercado.
} 
Ressalta-se que o incremento no preço da moradia é um reflexo dos arranjos e da lógica de reprodução do mercado imobiliário. Com efeito, o que correspondia a uma média de 35 mil pesetas por metro quadrado, no ano de 1987, passou a ser 70 mil pesetas no ano de 1988; e o preço médio das novas construções, que era de 60 mil, passou a ser, no mesmo ano, 103 mil por metro quadrado. Assim, tal

[...] injeção econômica feita em Barcelona, calculada à volta de um bilhão de pesetas, autoriza a pensar que o importante incremento no preço do alojamento iniciado na cidade se difundiu depois pela área metropolitana. Também é legitimo admitir que as diferenças de preços entre os bairros se mantiveram e que os incrementos afetaram quase homogeneamente toda a cidade (TELLO; RIGOL, 1994, p. 64-65).

Já no período entre os anos de 1987 e 1993, conforme a Tabela 01, houve uma considerável ascensão da variação no preço do metro quadrado das novas moradias construídas nos distritos da cidade de Barcelona. Notava-se, nos distritos de SantsMontjuic, Nou Barris, Sant Andreu e San Martí, um aumento da variação dos preços em torno de $180,99 \%, 177,72 \%, 171,62 \%$ e $180,99 \%$, respectivamente. Consequentemente, foram os distritos que foram mais afetados pelas operações de transformações urbanas decorrentes do plano estratégico e da vinculação com os Jogos Olímpicos de 1992.

Tabela 01: Variação do preço do metro quadrado de novas habitações em Barcelona (1987-1993).

\begin{tabular}{|l|c|}
\hline \multicolumn{1}{|c|}{ Distrito } & \multicolumn{1}{c|}{$\begin{array}{c}\text { Variação do preço } \\
\text { no período 1987-1993(\%) }\end{array}$} \\
\hline Eixample & 152,83 \\
\hline Gracia & 118,10 \\
\hline Horta-Guinardó & 86,30 \\
\hline Les Corts-Pedralbes & 108,82 \\
\hline Nou Barris & 177,72 \\
\hline Sant Andreu & 171,62 \\
\hline Sant Martí & 162,70 \\
\hline Sants-Montjuic & 180,99 \\
\hline Sarrià-Sant Gervasi & 114,10 \\
\hline
\end{tabular}

Fonte: Adaptado de (TELLO; RIGOL, 1994). 
De acordo com Herce $\left(2005\right.$, p. 46, tradução nossa) ${ }^{15}$, o caso de Barcelona está associado a pressões especulativas sobre "[...] terra valorizada em curto prazo que é produzida na periferia com as novas vias que aumentam fortemente o preço dessas áreas, e compõem uma onda que é transmitida para o centro, aumentando também o preço deste".

O preço, ou melhor, o "valor da terra" e, por conseguinte, o da moradia, pressupõem reflexos do racionamento capitalista em busca do controle das condições de lucro advindas das localizações dos terrenos na capital catalã. Portanto, essa disputa resultante das estratégias montadas e da transformação urbana gerada - e induzida - é possivelmente também responsável tanto pela segregação socioespacial quanto por uma divisão seletiva do espaço, entendidos enquanto forma e processo, visando ao controle espacial e à valorização imobiliária. Assim, a partir dessa exposição, entende-se, em uma provocação de Herce $\left(2005\right.$, p. 46, tradução nossa) ${ }^{16}$, que "na prática, eles são um reflexo da concentração da promoção em poucas mãos, em um processo do tipo oligopolista que pode acabar ditando as regras de configuração do modelo territorial" em Barcelona e em seus espaços circundantes. Fenômeno estabelecido pela vigorosa reflexividade econômica e pelo acumulado aprendizado estratégico, competitivo e de controle espacial (STORPER, 1997) vigentes na cidade e sua região de influência catalã.

Entre 1986 e 1992, o número de novas casas para venda em Barcelona aumentou quase $101 \%$. Tal fenômeno, longe de viabilizar o acesso à moradia, teve um impacto negativo na acessibilidade, refletindo também um significativo encarecimento dos preços de venda de novas unidades residenciais. Como resultado da nova regulamentação habitacional, os valores das unidades habitacionais para alugar, semelhantemente, elevaram-se no período acima citado.

No período entre os anos de 1986 e 1993, o aumento acumulado foi de quase $145 \%$ nos preços de novos imóveis. Ao mesmo tempo, a oferta de casas para alugar diminuiu gradualmente: entre 1981 e 1991, houve uma diminuição de 23,69\%. A disponibilidade de moradia pública e social foi drasticamente reduzida: entre 1986 e 1992, havia uma cumulativa redução em torno de 75,92\% em habitação pública disponível. Ora, enquanto os Jogos Olímpicos ajudaram a promover a marca "Barcelona" como um destino turístico internacional, eles favoreceram significativamente, via valorização imobiliária, o encarecimento do preço da habitação.

\footnotetext{
15 “[...] terrenos puestos en valor por el acortamiento de tiempo producido en la periferia con las nuevas carreteras las que incrementan fuertemente el precio en estas áreas, y conforman una onda que se transmite hacia el centro, incrementando también el precio de éste".

16 "en la práctica no son más que el reflejo de la concentración de la promoción en pocas manos, en un proceso de tipo oligopolista que puede terminar por dictar las reglas de conformación del modelo territorial".
} 


\section{Por trás da vitrine: remoções, despejos e reassentamento de comunidades}

Nas últimas décadas, observa-se um agravamento dos "efeitos colaterais" sobre a estrutura socioespacial de cidades-sede de megaeventos esportivos. Dada a amplitude desses impactos, precisamente entre as Olimpíadas de Seul 1988 e os Jogos de Pequim em 2008, mais de 2 milhões de pessoas foram afetadas. Impactos esses que, na maioria das vezes são devastadores sobre os grupos menos desfavorecidos, derivam de uma política excludente de embelezamento de cidade $^{17}$, de uma feroz implementação de grandes projetos de infraestrutura urbana e do consequente processo esmagador de valorização fundiária e imobiliária. Como já discutido, as estratégias para viabilizar um megaevento são parte de uma pactuada agenda política urbana, cuja força motriz é, precipuamente, promover o crescimento econômico local e colocar a cidade-anfitriã na agenda mundial (HALL, 1992). Porém, tais estratégias também culminam, na maioria dos casos, em um número considerável de desapropriações indevidamente empregadas, encarecimento habitacional, desocupações e remoções (forçadas) e na violação de direitos humanos ${ }^{18}$. Dados o modelo e a forma do sistema político-econômico hegemônico, a força motriz que tanto fomenta grandes projetos de infraestrutura urbana quanto angaria megaeventos tem, na materialização deles, as insígnias desse processo.

Destarte, pesquisadores do Centre on Housing Rights and Evictions - COHRE, sediado em Genebra, realizaram uma pesquisa em meados de 2007 sobre a situação dos afetados com as remoções resultantes de megaeventos esportivos. Cabe destacar que, durante esse estudo, uma série de entrevistas (abertas e semiestruturadas) foi efetuada com cerca de 30 agentes alvos das intervenções citadas. As informações foram compiladas e, por conseguinte, dois documentos foram produzidos, cujos resultados evidenciaram uma situação preocupante: diversas famílias foram afetadas por meio da construção de empreendimentos desportivos e da transformação urbana associados aos Jogos Olímpicos de 1992.

De acordo com um dos relatórios produzidos pelo COHRE, em conjunto com o Obervatório DESC, em Barcelona, denominado de Barcelona 1992: International Events and Housing Rights: a Focus on the Olympic Games (OBSERVATÓRIO DESC, 2007), o processo de realojamento e de remoção dos grupos afetados por meio da consecução das obras das instalações desportivas, bem como daquelas derivadas dos projetos de intervenção urbana, teve dois pontos fracos: i. Não houve interlocução ativa com os grupos afetados no início do processo; ii. As negociações das compensações e/ou indenizações não foram coletivas.

\footnotetext{
${ }^{17}$ Aqui, convém mencionar os megaprojetos e programas de gentrificação, seafront e ou waterfront development, revitalização urbanos, entre outros.

${ }^{18}$ Os Estados devem tomar medidas apropriadas para assegurar a consecução do direito humano à moradia, bem como as formas de proteção contra remoções forçadas e os tipos de violação desses direitos, tal como previsto no artigo 11 do Pacto Internacional de Direitos Econômicos, Sociais e Culturais.
} 
No concernente ao primeiro ponto, adicionalmente, não houve quaisquer evidências de um processo de consulta participativa aos grupos afetados (também não houve envolvimento dos mesmos na elaboração dos projetos e planos de remoção), seja antes, durante a preparação da candidatura ou durante o período a posteriori.

Entretanto, ao longo do processo de realojamento, foram instituídos acordos com a Câmara Municipal de Barcelona, através da realização de assembleias. Além disso, com as preocupações dos grupos expressas em relação à construção das autoestradas (Ronda de Dalt e Ronda Litoral), algumas demandas foram recebidas pelos representantes da Câmara.

Merece destaque ponderar que os grupos afetados, em parte, viviam em moradias antigas e que estavam em condições precárias e/ou fora das diretrizes do planejamento urbano catalão, bem como sem a devida segurança de posse. Dessa forma, viabilizados pelo processo de realojamento, esses grupos obtiveram acesso a moradias com melhores condições, apesar de que muitas famílias afetadas foram obrigadas a sair de seus bairros de origem.

Cabe ressalvar que, no início do processo de remoção, nem a Câmara Municipal, nem as empresas criadas para realizar os projetos mantiveram conversações com os afetados. Assim sendo, uma notificação oficial (ação denominada de desahucio na Espanha) anunciando que eles deveriam deixar suas casas foi a primeira notícia que receberam do processo de remoção e realojamento.

Dessa forma, com o fito de negociar com os grupos afetados, um estudo financeiro a respeito do processo de desahucio y desplazamiento foi conduzido. Em linhas gerais, o orçamento direcionado à compensação foi publicado em planos urbanísticos e a Câmara Municipal de Barcelona viabilizou esse processo através de:

i. As empresas criadas para a preparação e provisão dos empreendimentos desportivos e urbanos (Anella Olímpica de Montjuïc SA - AOMSA, Vila Olímpica SA - VOSA e Institut Municipal de Promoció Urbanística SA IMPUSA) tiveram a responsabilidade de negociar a compensação financeira e o realojamento das famílias afetadas;

ii. O Patronat Municipal de l'Habitatge - PMH, a Câmara Municipal e a Secretaria de Habitação de Barcelona, bem como a Societat Urbanística Metropolitana de Rehabilitació $i$ Gestió, SA - REGESA foram as entidades responsáveis pela provisão de unidades habitacionais destinadas aos grupos afetados.

\section{Remoções em função de Barcelona'92}

Mesmo que parte das instalações olímpicas tenha sido construída em áreas não residenciais, essas infraestruturas afetaram negativamente os residentes em áreas de abrangência das zonas olímpicas. No entanto, o Observatório DESC (2007) é enfático em concluir que grande parte das remoções não foi forçada, bem como os processos de 
realojamento dos grupos atingidos viabilizaram unidades habitacionais adequadas ou concederam compensação e indenização financeira.

A construção das instalações olímpicas e de outros projetos de infraestrutura urbana e/ou desportiva, associados ou não, afetou um total de 624 famílias (Tabela 02). Três principais áreas foram alvo de despejos: uma primeira área envolve um conjunto de bairros nas proximidades da Vila Olímpica; uma segunda área compreende a área onde se encontra a colina Montjuïc (onde estava localizado o Estádio Olímpico e outras instalações olímpicas); e uma terceira área incluía os bairros onde foram implantados os novos anéis viários (as denominadas rondas, em espanhol).

Tabela 02: Localização e quantidade de famílias afetadas por projetos dos Jogos de Olímpicos de 1992

\begin{tabular}{|c|c|c|c|c|}
\hline \multirow[b]{2}{*}{ Tipo de Projeto } & \multicolumn{4}{|c|}{ Localização } \\
\hline & \multicolumn{2}{|c|}{ Município } & Remoções em & $\begin{array}{l}\text { Quantidade } \\
\text { de famílias } \\
\text { removidas }\end{array}$ \\
\hline $\begin{array}{l}\text { Construção da Vila } \\
\text { Olímpica }\end{array}$ & \multicolumn{2}{|l|}{ Barcelona } & Poblenou & 147 \\
\hline \multirow{2}{*}{$\begin{array}{l}\text { Construção de anéis } \\
\text { viários (Ronda de } \\
\text { Dalt) }\end{array}$} & \multicolumn{2}{|l|}{ Barcelona } & $\begin{array}{l}\text { Comunidade } \\
\text { Bloque Fantasma }\end{array}$ & 65 \\
\hline & \multicolumn{2}{|l|}{ Barcelona } & $\begin{array}{l}\text { Comunidade Las } \\
\text { Casas del } \\
\text { Comandante }\end{array}$ & 18 \\
\hline \multirow{2}{*}{$\begin{array}{l}\text { Construção de anéis } \\
\text { viários entre } \\
\text { Barcelona e Área } \\
\text { Metropolitana }\end{array}$} & \multicolumn{2}{|c|}{$\begin{array}{l}\text { Santa Coloma de } \\
\text { Gramanet }\end{array}$} & $\begin{array}{l}\text { Comunidade La } \\
\text { Pata Norte }\end{array}$ & 52 \\
\hline & \multicolumn{2}{|c|}{$\begin{array}{l}\text { L'Hospitalet de } \\
\text { Llobregat }\end{array}$} & $\begin{array}{l}\text { Comunidade La } \\
\text { Pata Sul }\end{array}$ & 60 \\
\hline \multirow{4}{*}{$\begin{array}{l}\text { Projetos de } \\
\text { regeneração urbana }\end{array}$} & Barcelona & \multirow{3}{*}{$\begin{array}{l}\text { Distrito de } \\
\text { Sant Martí }\end{array}$} & $\begin{array}{l}\text { Comunidade } L a \\
\text { Perona }\end{array}$ & 102 \\
\hline & Barcelona & & $\begin{array}{l}\text { Comunidade Camp } \\
\text { de La Bota }\end{array}$ & 60 \\
\hline & Barcelona & & $\begin{array}{l}\text { Comunidade } \\
\text { Transcementiri }\end{array}$ & 100 \\
\hline & Barcelona & $\begin{array}{l}\text { Distrito de } \\
\text { Sants } \\
\text { Montjuïc }\end{array}$ & $\begin{array}{l}\text { Comunidade Can } \\
\text { Valero Petit }\end{array}$ & 20 \\
\hline & & & Total & 624 \\
\hline
\end{tabular}

Fonte: Elaborado pelo autor a partir de dados do Observatório DESC (2007). 
De fato, conforme o Observatório DESC (2007), a via conduzida pelo processo de realojamento dos grupos afetados teve duas principais deficiências:

i. Ausência de comunicação ativa com os afetados no início do processo;

ii. As negociações associadas à compensação do desalojamento foram conduzidas individualmente, em função dos conflitos gerados e das discordâncias dos valores inicialmente propostos.

Ademais, 147 famílias afetadas viviam em antigas habitações industriais localizadas na área do Poblenou, no distrito de San Martí (Figura 01), as quais estavam em condições precárias e sem segurança da posse. Outras famílias afetadas estavam localizadas em diversas áreas também em San Martí: 102 em na comunidade La Perona, 60 em Camp De La Bota e 100 em Transcementiri.

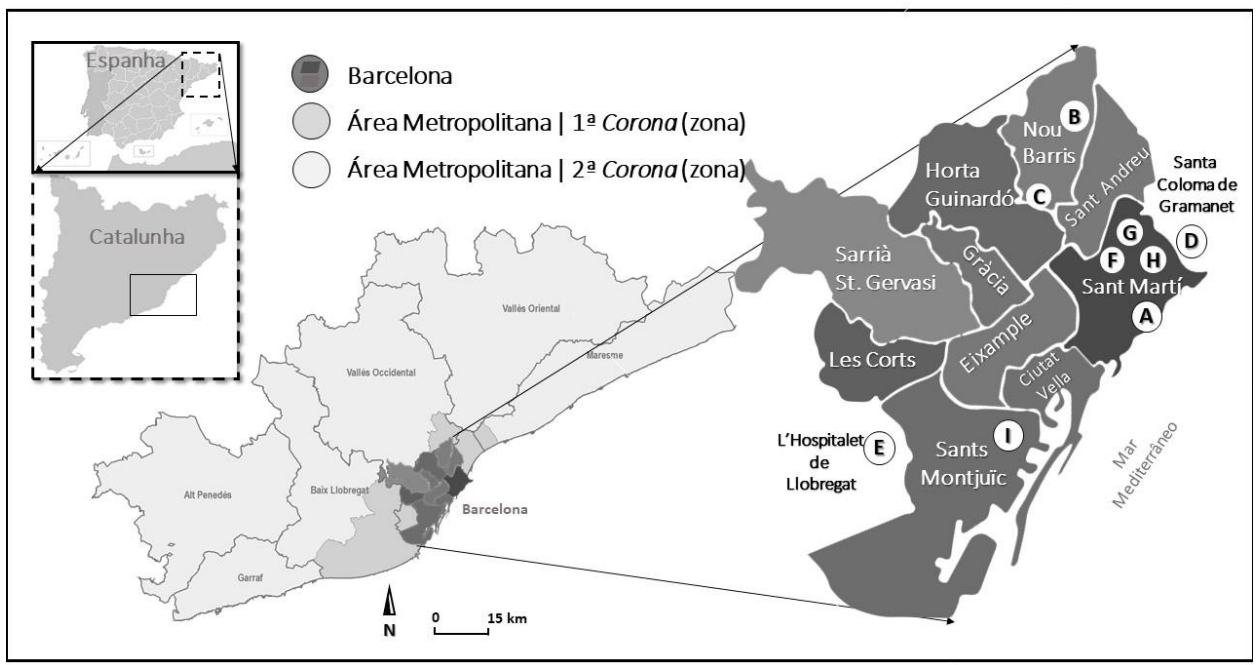

Figura 01: Localização das comunidades removidas.

Legenda: A - Famílias removidas no Bairro Poblenou, B - Bloque Fantasma, C - Las Casas Del Comandante, D - La Pata Norte, E - La Pata Sul, F - La Perona, G - Camp De La Bota, H Transcementiri, I - Can Valero Petit.

Fonte: Elaborado pelo autor.

As famílias e os grupos que foram vitimados pelas remoções tiveram como opções de realojamento casas disponibilizadas pelo PMH ou apartamentos subsidiados pelo Estado. Dentro dessa opção, os grupos afetados, qualquer que seja sua anterior situação, também poderiam escolher dentre as seguintes alternativas, a saber:

i. Compra de casa subsidiada pelo Estado (a um preço inferior ao preço de mercado). A diferença entre a compensação financeira atribuída à residência expropriada e ao preço da moradia onde o residente seria realocado foi compensada com um empréstimo hipotecário a uma taxa de juros mais baixa do que a taxa de mercado; 
ii. Os empréstimos hipotecários representaram entre $10 \%$ e $40 \%$, em média, o preço final da moradia. Na maioria dos casos, os empréstimos foram obtidos para montantes entre um e cinco milhões de pesetas (entre 6.000 e $30.000 €$ );

iii. Aluguel de uma casa subsidiada pelo Estado (de baixa renda do mercado). Aqueles que não conseguiram ou não quiseram comprar uma casa optaram por alugar, com valores abaixo do preço de mercado;

iv. Ocupação pelos idosos de casas subsidiadas pelo Estado com uma concessão até o fim da vida.

Em caso de falecimento de todos os ocupantes das casas usadas no realojamento, o PMH recuperaria tal unidade habitacional. A maioria das pessoas da área da Vila Olímpica que optou por casas do PMH foi realojada no Llevant Sud, um conjunto de imóveis compostos por um total de 322 unidades residenciais. Todavia, essas unidades na área do Llevant Sud não haviam sido construídas com essa finalidade, mas foram usadas para realocar as pessoas afetadas na área do Parc de Mar.

\section{Despejos na área industrial do Poblenou}

A câmera municipal de Barcelona estabeleceu a empresa VOSA como a responsável pelas expropriações relacionadas à construção da vila olímpica no bairro Poblenou. De acordo com o estudo do Observatório DESC (2007), a câmera ficou responsável pelas ações administrativas, enquanto a VOSA ficava à frente das remoções, do processo de compensação e dos realojamentos de 147 das famílias afetadas. Com efeito, a maioria dessas famílias e das pessoas afetadas fora realocadas nas unidades habitacionais do PMH, inseridas no LLevant Sud, também em Barcelona.

No mesmo bairro, 150 fábricas de uma área industrial foram igualmente afetadas e expropriadas com as transformações urbanas que estavam associadas ou não aos Jogos Olímpicos. Nesse contexto, a Associació d'Indústries Afectades (Associação de Indústrias Afetadas) foi criada pelos proprietários para levar a cabo as negociações e o processo de compensação.

Dessa forma, cerca de $95 \%$ das negociações foram conduzidas por mútuo acordo e 5\% tiveram de ser submetidos a atos administrativos de uso e ocupação dessa antiga área industrial da cidade, localizada sobretudo no Poblenou (OBSERVATÓRIO DESC, 2007).

\section{Erradicação de barraques remanescentes}

Objetivando requalificar e reutilizar os espaços urbanos considerados degradados ou abandonados para além da intervenção urbanística habitacional, pensa-se igualmente na implementação de áreas verdes, na mobilidade e na acessibilidade por meio de projetos de regeneração urbana (VÁZQUEZ, 2005; LOPES, 2011), e não somente pelos projetos 
de renovação ou reabilitação urbanos ${ }^{19}$. Assim sendo, estrategicamente a regeneração urbana surge "da necessidade de alteração ou reestruturação funcional de uma determinada área de intervenção e, portanto, é também resultado de uma opção estratégica de aproveitamento de uma determinada oportunidade" (MENDES, 2013, p. 37). Tal processo deve ser considerado de forma integrada ao responder espacialmente a critérios de intervenção sociais, econômicos e ambientais.

O processo de regeneração urbana desencadeado na capital catalã também intencionava suprimir toda sorte remanescente de assentamentos irregulares e ilegais. Denominados de barracas $^{20}$ ou barrios de chabolas (em espanhol e barraques, em catalão), as áreas dessas comunidades foram contempladas por um projeto de urbanização de áreas desfavorecidas. Em outras palavras, objetivou-se remover seus ocupantes e erradicar todo tipo de barraques remanescentes nas áreas destinadas ou próximas às intervenções urbanas e olímpicas.

Comunidades foram totalmente suprimidas através da execução de projetos de regeneração urbana e de novos (e/ou de readequação dos existentes) empreendimentos de mobilidade: La Perona, Camp de La Bota, Transcementiri e a comunidade Can Valerio Petit.

\section{i. La Perona}

Comunidade que teve como origem o ano de 1947, em que a constituição de aproximadamente 400 barracas coincidiu com a visita de Eva Peron. No ano de 1966, essa comunidade foi expandida com a chegada de muitas famílias ciganas que foram removidas da área das barraques del Somorrostro ${ }^{21}$. O povo cigano, que fora removido de suas casas, ainda era historicamente vítima de preconceito e segregação.

O processo de realojamento foi iniciado em 1982, ou seja, antes da candidatura de Barcelona aos Jogos Olímpicos. Entretanto, fazia parte de um projeto de erradicação de barracas na década de 1980 que deveria ser efetivado antes do megaevento esportivo de 1992. Após um processo em que ocorreu tensão e oposição ao realojamento, algumas das famílias foram realocadas por meio da empresa PMH, na área de Besòs-Maresme.

\section{ii. Camp de La Bota}

\footnotetext{
19 "Na reabilitação urbana, alega-se o respeito pelo carácter arquitetônico dos edifícios, ao passo que na renovação urbana é permitido o processo mais ou menos pontual de demolição e reconstrução. A renovação urbana é uma ação que implica a demolição das estruturas morfológicas e tipológicas existentes numa área urbana degradada e a sua consequente substituição por um novo padrão urbano, como novas edificações" (MENDES, 2013).

${ }^{20}$ Barracas era a denominação utilizada para favela e/ou casas precárias. As áreas de barracas na capital da Catalunha se estendiam pela zona litorânea, pela montanha de Montjuïc, também junto aos pés de Collserola e por outras colinas.

${ }^{21}$ Extinto em meados de 1966, Somorrostro era a denominação dada ao intenso aglomerado residencial que se formou na zona litorânea de Barcelona, precisamente entre os distritos de San Marti e Ciutat Vella.
} 
Sessenta famílias que ocupavam uma área denominada de Camp de La Bota, que se estendia desde a Rambla de Poblenou até Besòs. Área em que, atualmente, encontramse a Ronda Litoral e as praias recuperadas após a expropriação dessa comunidade. De uma maioria constituída por ciganos, as famílias foram realocadas nos distritos de Sants, Sant Marti e Sant Andreu.

iii. $\quad$ Transcementiri

Cerca de 100 famílias ocupavam a comunidade Transcementiri (Figura 02). Tratava-se de uma área que não seria afetada, a princípio, mas a construção das Rondas levou a cabo o processo de expropriação dessa comunidade, majoritariamente ocupada por famílias de ciganos. Tanto as remoções quanto o realojamento ocorreram entre 1988 e 1989, em que cem unidades habitacionais providenciadas pelo Institut Municipal de Promoció Urbanística SA - IMPUSA (Instituto Municipal de Desenvolvimento Urbano) foram entregues aos afetados.

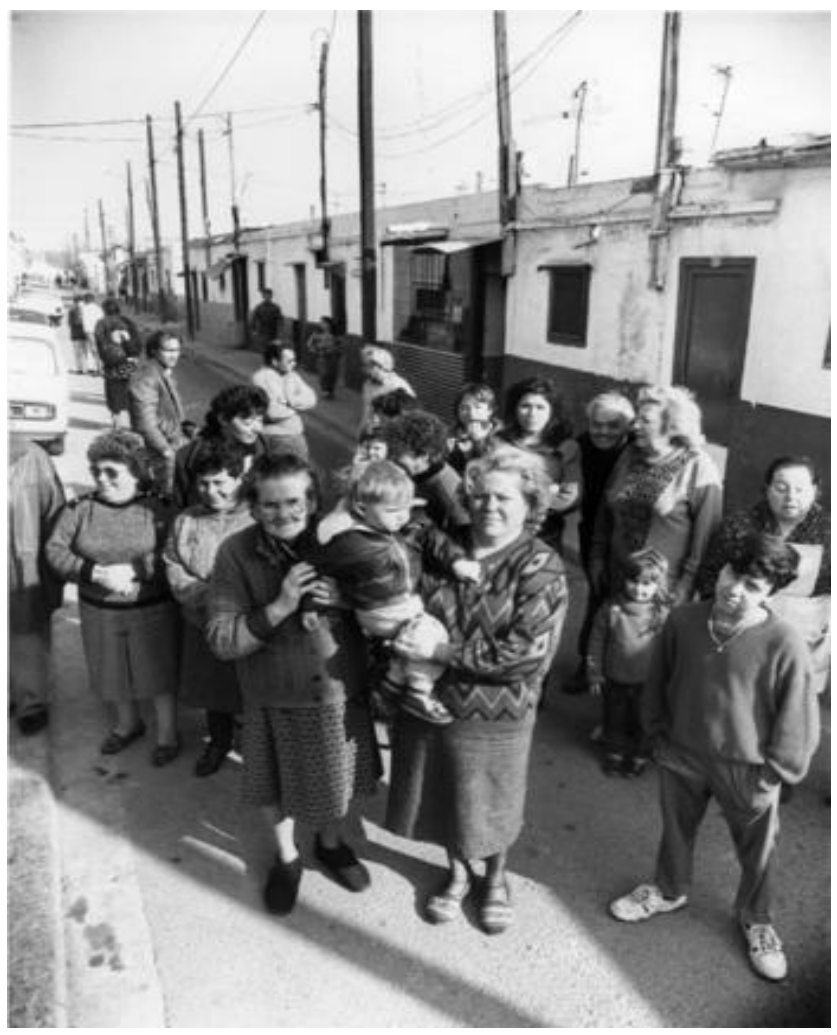

Figura 02: Moradores da extinta Comunidade Transcementiri em um dia de protesto contra as remoções e construção da Vila Olímpica, em 1989.

Fonte: Arxiu Històric del Poblenou. 


\section{iv. $\quad$ Distrito de Sants-Montjuïc: A remoção da comunidade Can Valero Petit}

Localizada na colina de Montjuïc, a comunidade Can Valero Petit, na época das remoções e deslocamentos, contava com vinte famílias de ciganos. As origens dessa comunidade remontam ao século XVIII, quando a área foi ocupada por trabalhadores nas pedreiras existentes na colina. Segregada historicamente, tratava-se de uma ocupação que cresceu de forma irregular, uma vez que acompanhou os fluxos migratórios gerados pelo crescimento vertiginoso da cidade. Conforme o Observatório Desc (2007), no ano de 1966 havia aproximadamente 12.000 unidades habitacionais (barraques) no perímetro da comunidade e algumas famílias vivendo nas ruínas do estádio da Exposição Universal de 1929. Quando as pedreiras foram transformadas em aterros, por volta de 1953, as condições de vida na área deterioraram-se ainda mais.

Em 1975, após uma série de processos nos quais se indicava a remoção das famílias que residiam no Can Valero Petit, ficava estabelecido o fim da prática de deposição de resíduos sólidos nos aterros existentes à época. Nesse período, 20 famílias ainda continuavam resistindo. Entre 1984 e 1986, as negociações e o processo de realojamento foram executados com as famílias de Can Valero Petit. Na maioria dos casos, as partes concordaram em um montante de compensação. No ano de 1987, dos remanescentes, entre cinco e sete famílias foram realojados na área de Can Clós.

\section{Remoções como consequência de obras de mobilidade}

Muitos também foram deslocados em nome das obras de construção e ou readequação do sistema de mobilidade existente, as quais tiveram um efeito direto sobre a destruição dos edifícios residenciais. A compensação foi negociada na maioria dos casos daqueles atingidos pelas desapropriações. Essas obras incidiram sobre quatro comunidades: Bloque Fantasma, Las Casas del Comandante, La Pata Norte e La Pata Sul.

\section{i. $\quad$ Comunidade Bloque Fantasma}

Sessenta e cinco famílias foram desalojadas da comunidade Bloque Fantasma, a qual estava inserida na área de construção do segundo anel rodoviário denominado de Ronda de Dalt (conhecido igualmente como B-20). As famílias removidas foram realocadas no bairro Nou Barris em Barcelona. Segundo relatório do Observatório Desc (2007), com uma duração total de um ano e seis meses, aproximadamente, o processo de realojamento providenciado pelas empresas PMH e IMPUSA foi lento e exaustivo ao grupo afetado.

\section{ii. $\quad$ Comunidade Las Casas del Comandante}

Também inserida em uma das áreas de construção do anel rodoviário Ronda de Dalt, encontrava-se a comunidade Las Casas Del Comandante. O processo de expropriação e de realojamento foi conduzido pelas empresas IMPUSA e REGESA. Sem o direito de propriedade legal, foram removidas dessa comunidade 18 famílias, as quais foram realocadas ou receberam compensação financeira. 


\section{iii. La Pata Norte}

Formado por uma grande parte de idosos, os moradores da antiga comunidade Pata Norte receberam, em 1989, as ações de negociações e de realojamento provenientes da empresa REGESA, durante quatro meses. De um total de 37 unidades habitacionais, as 52 famílias removidas em função da implantação da Ronda de Dalt foram realojadas no município de Santa Coloma de Gramanet, na Área Metropolitana de Barcelona.

\section{iv. La Pata Sul}

Na comunidade denominada de La Pata Norte, inserida no município de L'Hospitalet de Llobregat, 60 famílias foram afetadas pelas ações de remoção. A empresa IMPUSA negociou e gerenciou o processo de realojamento. Algumas das famílias tiveram que passar por julgamento, frente às dificuldades encontradas durante as expropriações (OBSERVATÓRIO DESC, 2007).

\section{Considerações Finais}

Tendo em vista o êxito de planejamento estratégico catalão, as preparações para o Barcelona'92 atingiram diversas famílias, por meio da construção de empreendimentos desportivos e de transformação urbana. Em se tratando de remoções, 624 famílias foram impactadas, ou seja, desalojadas das áreas designadas. Desse total, 147 famílias foram diretamente afetadas devido à construção da Vila Olímpica e 477 famílias foram indiretamente afetadas (282 devido à eliminação de assentamentos e 195 em função da implementação e/ou readequação do sistema viário). Ressalta-se ainda que $65 \%$ das famílias que viviam segregadas em assentamentos informais e/ou habitações precárias (as denominadas barraques) eram de origem cigana. Infelizmente, mesmo reassentado, o povo cigano ainda era vítima de preconceito e segregação.

Cumpre registrar que uma das principais fraquezas no processo de remoção e realocação foi a falta de mecanismos participativos. Semelhantemente, menciona-se uma ausência de alternativas aos despejos. Além disso, a estratégia de negociação individual dos acordos de compensação financeira resultou em uma fragmentação de interesses. De fato, o processo de realojamento e de remoção dos grupos afetados não mediou e proporcionou, inicialmente, interlocução ativa entre as partes envolvidas. Faz-se também necessário indicar que um padrão de habitação alternativa foi fornecido aos moradores acometidos pelas intervenções espaciais. Enfim, geograficamente diferenciada, a desocupação desses assentamentos significava impulsionar a valorização imobiliária das áreas vinculadas às transformações socioespaciais.

No que concerne ao encarecimento dos preços dos imóveis, constatou-se um aumento de cerca de $240 \%$ nos preços dos imóveis novos entre o anúncio de 1986, da eleição de Barcelona como cidade-sede e 1992, ano de celebração do Evento. Unidades habitacionais destinadas, preferencialmente, ao aluguel social, foram reduzidas. Mais do que isso, a construção de novas habitações de interesse social encolheu consideravelmente. 
Como testemunho desse processo, das transformações espaciais e da reprodução do capital, valorizou-se um padrão de desterritorialização e de seu correspondente modus operandi de segregação socioespacial em Barcelona. De um lado, percebeu-se a refuncionalização dos territórios e a polarização socioespacial: espaços qualificados, valorizados e espaços segregantes, pautados na gentrificação e na regeneração urbanos. Do outro, destacam-se espacialidades - periféricas, segmentais e/ou manchas residuais imbuídas de grupos segregados, onde os terrenos e as moradias são mais acessíveis e/ou mais baratos, evidenciando espaços de contradição.

\section{Referências}

ACEBILLO, J. A. El "model Barcelona" des del punt de vista urbanístic. Espai urbá i complexitat. In: MARAGALL i MIRA, Pasqual (eds.). Europa pròxima. Europa, regions, ciutats. Barcelona: Edicions Universitat de Barcelona/ Edicions UPC, 1999.

BOHIGAS, O. Revaloració de la perifèria i recuperació del centre. Reconversió del front marítim. In: MARAGALL i MIRA, Pasqual (eds.). Europa pròxima. Europa, regions, ciutats. Barcelona: Edicions Universitat de Barcelona/ Edicions UPC, 1999.

BRUNET, F. “An economic analysis of the Barcelona'92 Olympic Games: resources, financing and impact". In: MORAGAS, Miquel de; BOTELLA, Miquel. The Keys to Success: the social, sporting, economic and communications impact of Barcelona'92. Barcelona: Servei de Publicacions de la UAB, 1995.

BUSQUETS, J. Barcelona: la construcción urbanística de una ciudad compacta. Barcelona: Ediciones del Serbal, 2004.

CAPEL, H. El modelo Barcelona: un examen crítico. 2. ed. Barcelona: Ediciones del Serbal, 2009.

CENTRE ON HOUSING RIGHTS AND EVICTIONS (COHRE). Fair Play for Housing Rights: Mega-Events, Olympic Games and Housing Rights. Geneva: COHRE, 2007.

CLUSA, J. La experiencia olímpica de Barcelona 1986-1992 y las expectativas del Forum 2004. Cidades, 5, p.85-102, 1999.

ESSEX, S.; CHALKLEY, B. Las transformaciones urbanas a raíz de la celebración de los Juegos Olímpicos: lecciones universitarias olímpicas. Barcelona: Centre d'Estudis Olímpics (UAB)/Cátedra Internacional de Olimpismo (CIO-UAB), 2003.

GIULIANOTTI, R.; ARMSTRONG, G.; HALES, G; HOBBS, D. Global sport mega-events and the politics of mobility, The British Journal of Sociology, Volume 66, Issue 1, 2015.

HALL, C. M. Hallmark tourist events: the impacts, management, and planning of event tourism. New York: Belhaven Press, 1992. 
HARGREAVES, J. Freedom for Catalonia? Catalan Nationalism, Spanish Identity and the Barcelona Olumpic Games, Cambridge: Cambridge University Press, 2000.

HARVEY, D. A produção capitalista do espaço. Traduzido por Carlos Szlak. São Paulo: Annablume, 2005. 252p. (Coleção geografias e adjacências).

HERCE, M. Urbanización, precios del suelo y modelo territorial: la evolución reciente del Área Metropolitana de Barcelona. Revista Eure, XXXI, 93, p.35-51, 2005.

HILLER, H. H. Post-event outcomes and the post-modern turn: the olympics and urban transformations. European Sport Management Quarterly, 6, 4, p.317-332, 2006.

HOLSA. Los Juegos Olímpicos como generadores de inversión (1986-1992). Barcelona: Barcelona Holding Olímpic, 1992.

LIMA, E. L. V. Nas tramas e falácias do planejamento urbano estratégico: marketing urbano, modelo Barcelona e megaeventos. Bol. Goiano de Geografia (Online). Goiânia, v. 35, n. 2, p. 217-235, maio/ago. 2015.

LOPES, D. O. A reabilitação urbana em Portugal: Importância Estratégica para as Empresas do Setor da Construção Civil e Obras Públicas. Dissertação (Mestrado em Economia e Gestão das Cidades) - Faculdade de Economia, Universidade do Porto. Porto, 96p. 2011.

MARAGALL, P. L'esdeveniment com a estratégia de desenvolupament urbà: lês Olimpíades Del '92. In: MARAGALL i MIRA, Pasqual (eds.). Europa pròxima. Europa, regions, ciutats. Barcelona: Edicions Universitat de Barcelona/Edicions UPC, 1999.

MENDES, L. A regeneração urbana na política de cidades: inflexão entre o fordismo e o pósfordismo. Urbe. Revista Brasileira de Gestão Urbana (Brazilian Journal of Urban Management), v. 5, n. 1, p. 33-45, jan./jun. 2013.

MONCLÚS, F. J. Urbanismo olímpico y postolímpico. Visiones profesionales, académicas y periodísticas. Biblio 3W. Revista Bibliográfica de Geografía y Ciencias Sociales, Universidad de Barcelona, Vol. XV, no 895 (3), 5 de noviembre de 2010. Disponível em: <http://www.ub.es/geocrit/b3w-895/b3w-895-3.htm>. Acesso em: 9 dez. 2016.

MORAGAS, M. de; BOTELLA, M. de. Barcelona: l'herencia dels jocs (1992-2002). Barcelona: Centre d'Estudis Olímpics UAB, 2002.

NAYLON, J. Barcelona. In: PACIONE, Michael. Urban problems and planning in the developed World. London: Croom Helm, p.223-257, 1981.

OBSERVATÓRIO DESC. Barcelona 1992: International Events and Housing Rights: a Focus on the Olympic Games. Ginebra: COHRE, 2007.

OLDS, K. Urban Mega-Events, Evictions and Housing Rights: The Canadian Case. Current Issues in Tourism, 1, 1, p.2-46, 1998.

PREUSS, H. The economics of staging the Olympics: a comparison of the games, 19722008. Cheltenham, UK: Edward Elgar, 2004. 
ROCHE, M. Mega-Events and Modernity: Olympics and Expos in the Growth of Global Culture. London: Routledge, 2000.

ROCHE, M. Mega-events, Time and Modernity: On Time Structures in Global Society. Time \& Society, 12, 1, p.99-126, 2003.

SASSEN, S. The Global city: Introducing a concept. Brown Journal of Worlds Affairs, Winter/Spring, 11, 2, p.21-43, 2005.

SILK, M. Neoliberalism and Sports Mega-events. In: GRIX, Jonathan. Leveraging legacies from sports mega-events. Basingstoke: Palgrave Macmillan, 2014.

STORPER, M. The Regional World: Territorial Development in a Global Economy (Perspectives on Economic Change). New York, London: The Guilford Press, 1997.

TELLO, R.; RIGOL, S. M. Terciarização e encarecimento do alojamento em Barcelona. Finisterra, Revista Portuguesa de Geografia, XXIV, 57, p. 61-77, 1994.

TOURAINE, A. Après la crise. Paris: Editions du Seuil, 2010.

VALLS, J. El precio de compra venda de viviendas en Barcelona (1972-1996). In: VERGÉS, Ricardo (ed.). El precio de la vivienda y la formación del hogar. Barcelona: Centre de Cultura Comtemporània de Barcelona, 1998.

VALLS, X. Quan l'habitatge fa ciutat. Barcelona: Edicions Universitat Barcelona, 2001.

VÁZQUEZ, I. A Reabilitação do Património Edificado no Contexto da Regeneração Urbana. In: 2. ${ }^{\circ}$ Seminário - A Intervenção no Património. Práticas de Conservação e Reabilitação, 2005, Porto, Portugal. Anais... Faculdade de Engenharia da Universidade do Porto, 2005.

ZUKIN, S. Gentrification: Culture and Capital in the Urban Core. Annual Review of Sociology, v. 13, p.129-147, 1987.

Ernandy Luis Vasconcelos de Lima

Pós-doutor pela University of Oxford. Pós-doutor pela Universidade Federal do Ceará. Doutor em Geografía, Planificación Territorial y Gestión Ambiental pela Universitat de Barcelona. Mestrado Oficial Europeu em Planificación Territorial y Gestión Ambiental pela Universitat de Barcelona. Mestrado em Desenvolvimento e Meio Ambiente pela Universidade Federal do Ceará. Graduação (Bacharelado e Licenciatura) em Geografia pela Universidade Estadual do Ceará.

E-mail: ernandy@gmail.com 